\title{
Indicators of Oral Hygiene and Preventive Dental Care as Variables Associated with the High Severity of Caries
}

MS Herrera, ${ }^{1}$ CE Medina-Solís, ${ }^{2,3}$ NL Robles-Bermeo, ${ }^{3}$ E Lara-Carrillo, ${ }^{3}$ LJ GuadarramaQuiroz, ${ }^{2}$ JJ Navarrete-Hernández, ${ }^{2}$ JJ Villalobos-Rodelo, ${ }^{4}$ AP Pontigo-Loyola. ${ }^{2}$

\begin{abstract}
Objective: To identify if the presence of dental plaque, dental brushing frequency and preventive dental care are related to the high severity of dental caries.

Methods: A case-control study was carried out on a sample of schoolchildren aged 6 to 12 years. We selected 677 children from public schools in the city of León Nicaragua, 283 cases y 394 controls. Using questionnaires addressed to mothers / guardians, a series of sociodemographic, socioeconomic and dental variables were collected. Through oral clinical examination, the dmft and DMFT caries indexes were determined for primary and permanent dentition. The dependent variable was the high severity of caries, which was coded as (1) "dmft + DMFT $=0$ " and (2) "dmft + DMFT $\geq 6$ ". The chi-square test and the Mann-Whitney test were used in the statistical analysis.

Results: In the bivariate analysis, we observed that the associated variables $(\mathrm{p}<0.05)$ to high caries severity $(\mathrm{dmft}+\mathrm{DMFT} \geq 6)$ were: younger age of the child, younger age of the mother, less brushing frequency, presence of dentobacterial plaque and the pattern of dental care.

Conclusions: The results of the study show that the variables related to oral hygiene, both objective measurement (presence of dentobacterial plaque) and subjective measurement (selfreport of toothbrushing frequency), are associated with high severity of dental caries. In addition, according to the pattern of dental care showed association with the severity of caries.
\end{abstract}

Keywords: Caries severity, dental caries, Nicaragua, oral health, schoolchildren

Affiliations: ${ }^{1}$ Faculty of Dentistry of National Autonomous University of Nicaragua, Leon, Nicaragua, ${ }^{2}$ Academic Area of Dentistry of Health Sciences Institute at Autonomous University of Hidalgo State, Pachuca, ${ }^{3}$ Advanced Studies and Research Center in Dentistry "Dr. Keisaburo Miyata" of Faculty of Dentistry at Autonomous University State of Mexico, Toluca, and ${ }^{4}$ Department of Epidemiology at ISSSTE, Culiacan, Mexico.

Correspondence: Dr C Medina-Solís, Academic Area of Dentistry of Health Sciences, Institute, Autonomous University of Hidalgo State, Pachuca, Mexico.

Email: cemedinas@yahoo.com 


\section{INTRODUCTION}

Dental caries represents one of the major oral health problems around the world. It is a multifactorial disease caused by a physiological imbalance between the minerals of the tooth and the dentobacterial plaque, resulting in a net loss of dental mineral (1). Although in its initial stages it is reversible, once it sets in, it advances slowly, causing the destruction of the hard tissue of the tooth; if it is not restricted by proper dental treatment, it is one of the main causes of tooth loss. Once it occurs, as it is a cumulative disease, its manifestation persists throughout life even after treating the lesion (2). Despite being preventable in minimally protective ways, dental caries' shows a high prevalence and incidence and it is one of the unmet oral health needs among the Latin American population and mainly located among the most vulnerable population (3-5).

Through epidemiological indices, the prevalence, the incidence and the intensity or severity of dental caries in populations can be determined. The common indicators that have been used worldwide are the $\mathrm{dmft}$ and the DMFT indices. The $\mathrm{dmft}$ index (decayed, extracted/indicated for extraction and filled teeth) is commonly employed in studies about dental caries in primary dentition. On the other hand, the DMFT index reflects a similar evaluation in permanent teeth (6). Among school-age subjects, it has been observed that dental caries is distributed in a biased manner, with approximately $60-70 \%$ of the disease concentrated in $20 \%$ of the people (7).

This resulted in a different approach for dental treatment in the population, while the concentration of highly active caries in a small proportion of children raises the rational need for methods to identify those at risk of highly active caries, with the purpose of preventing or controlling it (8). Oral hygiene is an important goal towards improvement in oral health. One of the main recommendations in primary oral health is the mechanical removal of dentobacterial 
plaque through brushing, this is the educational message given to children, adolescents, and adults, as it helps to eliminate dental plaque and facilitates contact of fluoride in the toothpaste with the teeth (9); together with the massive strategies mentioned above, we can control the most prevalent oral disease. The aim of the study was to identify whether the presence of dental plaque and tooth-brushing frequency and preventive dental care are related to the high severity of dental caries in Nicaraguan children.

\section{MATERIAL AND METHODS}

\section{Study design and sample selection}

A case-control study was carried out based on data from a study on oral health, from which a set of oral health indicators (10-12) have been published. The inclusion criteria were apparently healthy children from 6 to 12 years of age, who were enrolled in primary schools. Their parents gave consent for their children to participate in the study, who did not have orthodontic appliances and did not have diseases that affect the oral cavity. Using the sampling strategy proposed by the OMS (13), in 25 public schools, four children and four girls from each of the seven groups of 6 to 12 years old were included, which in the end resulted in 56 children. Thus, in the original study, they were similarly distributed by age and gender, which elicited a sample

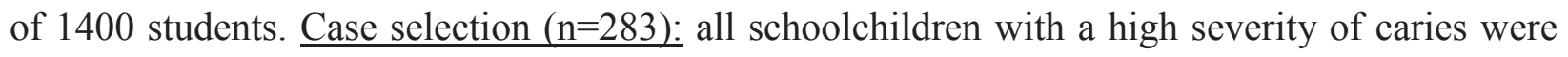

defined as cases, which means, the sum of their dmft and DMFT was 6 or more. Selection of $\underline{\text { controls }(n=394)}$, using the database with information from other schoolchildren as possible controls, all those students who were free of caries in both dentitions were selected. Thus, the final sample is 677 children. 


\section{Variables and data collection}

The dependent variable was the high severity of caries, which was coded as $0=\mathrm{dmft}+\mathrm{DMFT}=$ 0 and $1=\mathrm{dmft}+\mathrm{DMFT} \geq 6$. Which was calculated from the indices dmft and DMFT (decayed, missing and filled teeth index in the primary and permanent dentition, respectively). In the oral clinic inspection, a periodontal probe and intraoral mirror were used in daylight. The students were examined at the facilities of each educational institution, avoiding interference with educational activities. All subjects were clinically examined by one of two trained and standardized examiners (Kappa $>0.85$ ) on the caries criterion used. In a format designed for the study containing an odontogram, the results of the clinical variables were established.

For the collection of sociodemographic, socioeconomic, and dental variables, questionnaires were distributed to the mothers/guardians of the children, which were then delivered to the schools and later collected via the same route. At the same time, the signed letter of consent was requested. The independent variables included in the study were: age, gender, birth order, dental brushing frequency, dental plaque and type of dental care service used in the last year by the child. Age and attitude of the mother towards oral health; the size of the family; and schooling and occupation of the parents, calculating with this information the socioeconomic position of the family.

From the dental plaque, its presence or absence was determined using the modified Silness and Löe index (14), by inserting the tip of a probe into the gingival groove and sliding it around all the teeth, the plaque extension was registered at the end (number of teeth with presence of plaque divided by the total of teeth, multiplied by 100) and was coded as $0=$ low presence (individual presenting a plaque extension of less than $20 \%$ ) and $1=$ high presence (individual presenting an extension of plaque $>20 \%$ ). The importance attributed by the mother 
to the oral health of the children was reduced to a positive attitude (1) if she answered "yes" to the following two questions: Do you consider it important that your child's teeth are kept in good condition? Have you ever examined your child's teeth to determine if they were healthy? A negative attitude (0) was registered if there was a "no" response to either of these two questions. This approach has been used in several studies $(15,16)$. The socioeconomic position (SEP) was assigned according to the occupation and schooling of the father and mother. To assign a group of SEP, the principal components analysis methodology was used, generating two indicators, one for parental schooling and one for occupation (17). The variables generated explained $80.2 \%$ and $55.8 \%$ of the variability, respectively. Terciles were calculated for both, in which the first one was referred to the group with the worst socioeconomic position and the fourth to the group with the best socioeconomic position.

\section{Analysis of data}

The univariate analysis reported measures of central tendency and dispersion for quantitative variables, while frequencies and percentages were reported for qualitative variables. In the bivariate analysis, the chi-square and Mann-Whitney tests were used, according to the measurement scale of the variables tested.

\section{Ethical considerations}

The accomplishment of this study fulfilled the specifications of protection to the study participants and adhered to the ethical and research regulations in force of the National Autonomous University of Nicaragua (Campus León). Informed consent was signed by the parents/guardians of the students and the information was treated as confidential. 


\section{RESULTS}

The study included 677 schoolchildren, 283 cases and 394 controls. Table 1 shows the results of the descriptive and bivariate analysis. In the Mann-Whitney test, the age of school children was lower in those with high caries severity $(8.07 \pm 2.13$ vs $9.56 \pm 2.13 ; p<0.0001)$ than in cariesfree children. The age of the mother was lower in those with high severity of caries $(31.84 \pm 5.90$ vs $33.38 \pm 5.93 ; p<0.001)$ than in caries-free children. When the chi-square test was performed, it was observed that the percentage of subjects with high caries severity was worse among children who reported less tooth brushing $(\mathrm{p}<0.001)$, and who had more dentobacterial plaque $(\mathrm{p}<0.001)$. Students with a pattern of preventive dental care had a lower frequency of high caries severity $(\mathrm{p}<0.001)$. We did not observe statistically significant differences $(\mathrm{p}>0.05)$ by gender, birth order, mother's attitude towards children's oral health, family size, and socioeconomic position.

\section{DISCUSSION}

In this study, it was observed that oral hygiene and dental care are associated with the high severity of dental caries in this sample of Nicaraguan school children. For many years, the overall goal of the World Health Organization (WHO) for dental caries in 2000 was no more than an average of 3 decayed, missing, or filled teeth at 12 years of age - which has been used as an overall pattern for the success of oral health programs. Likewise, the use of different cut-off points of dmft and DMFT to establish the severity and prevalence of caries is an accepted practice in the dental community and has been used to assess prevalence in various studies around the world (18). 
Inadequate access to dental care for children from low-income families may be due in large part to the lack of dental insurance. Despite improvements in the oral health of children through prevention, dental caries remains one of the most common chronic diseases of childhood around the world (19). In this study, children with preventive dental care patterns showed the lowest percentage of caries severity. Similar findings have been observed in other studies: for example, Ditmyer et al. (20) report that subjects with fissure sealants, which is one of the preventive procedures performed by dentists in children, have higher levels of caries severity. A series of meta-analyses recently published on the application of fluoride rinse (21), gel (22), and varnishes (23), along with preventive actions carried out in the dental clinic, found clear evidence that fluoride has an effect on the reduction of caries in the primary and permanent dentition.

There are several studies that relate to oral hygiene, either by measuring it with the presence of dentobacterial plaque or by toothbrushing frequency, with dental caries $(6,24-26)$, showing that the presence of dentobacterial plaque is a risk factor for dental caries, whereas the greater frequency of dental brushing is a protective factor against it. Dental brushing with fluoride paste removes dental plaque present on dental surfaces, which is considered important to do at least twice a day. Therefore, programs should be established to help parents create a daily habit of brushing their children's teeth $(25,27)$. The study has limitations that must be addressed for adequate interpretation of the results. For example, cross-sectional studies present the problem of temporal ambiguity, where causal relationships cannot be achieved between the dependent and independent variables. Another issue is introducing memory bias in self-report studies. However, this is used in most epidemiological studies and is a valid way to obtain data. 


\section{CONCLUSION}

The results of the survey show that the variables related to oral hygiene, including objective measurements (presence of dentobacterial plaque) and subjective measurements (report of tooth brushing frequency), are associated with better dental health when practiced consistently. The pattern of dental care (or lack of one) shows an association with the severity of caries. It is necessary for oral health programs to include an addition to the preventive component or a curative component, to meet their oral health needs.

\section{AUTHORS' NOTE}

MS Herrera and CE Medina-Solís, were involved in the design and development of the study. C.E.M.S. designed the study, did the analysis of the data and wrote the first draft of the manuscript. NL Robles-Bermeo, E Lara-Carrillo, LJ Guadarrama-Quiroz, JJ NavarreteHernández, JJ Villalobos-Rodelo and AP Pontigo-Loyola, were involved in the conception of the paper, analysis and interpretation of the results. All the authors were involved in the critical review and made intellectual contributions, they also accepted the final version. The authors declare that they have no conflicts of interest. 


\section{REFERENCES}

1. Fejerskov O. Changing paradigms in concepts on dental caries: consequences for oral health care. Caries Res 2004; 38: 182-91.

2. Selwitz RH, Ismail AI, Pitts NB. Dental caries. Lancet 2007; 369: 51-9.

3. Ravera E, Sanchez GA, Squassi AF, Bordoni N. Relationship between dental status and family, school and socioeconomic level. Acta Odontol Latinoam 2012; 25: 140-9.

4. Ferreira-Gaona MI, Diaz-Reissner CV, Pérez-Bejarano NM, Sanabria-Vázquez DA, Alvarenga-Rodas MV, Diosnel-Bazán D. Oral health in preschoolers and level of knowledge about oral hygiene of their mothers, in public and private schools in San Lorenzo, Paraguay. Pediatr (Asunción) 2016; 43: 129-36.

5. Medina-Solís CE, Pontigo-Loyola AP, Mendoza-Rodríguez M, Lucas-Rincón SE, Márquez-Rodríguez S, Navarrete-Hernandez JJ, et al. Treatment needs for dental caries, restorative care index, and index of extractions in adolescents 12 to 15 years old. West Indian Med J 2013; 62: 636-41.

6. Segovia-Villanueva A, Estrella-Rodríguez R, Medina-Solís CE, Maupomé G. Severidad de caries en preescolares bajo un programa de odontología preventiva. Rev Salud Publica (Bogota) 2005; 7: 56-69.

7. Stamm JW, Disney JA, Graves RC, Abernathy JR. The University of North Carolina caries risk assessment study I: Rationale and content. J. Public Health Dent 1988; 48: $225-32$.

8. Stamm JW, Stewart PW, Bohannan AM, Disney JA, Graves RC, Abernathy JR. Risk assessment for oral diseases. Adv Dent Res 1991; 5: 4-17. 
9. Villalobos-Rodelo JJ, Lau-Rojo L, Ponce de León-Viedas MV, Verdugo-Barraza L, Valle-Villaseñor JF, Guzmán-Fonseca TJ. Prácticas de cepillado dental en escolares de seis a 12 años de edad y factores asociados. Rev Mex Pediatr 2006; 73: 167-71.

10. Herrera MS, Medina-Solís CE, Minaya-Sánchez M, Pontigo-Loyola AP, VillalobosRodelo JJ, Islas-Granillo H, et al. Dental plaque, preventive care, and tooth brushing associated with dental caries in primary teeth in schoolchildren of Leon, Nicaragua ages 6-9 years. Medical Sci Monit 2013; 19: 1019-26.

11. Herrera MS, Medina-Solís CE, Islas-Granillo H, Lara-Carrillo E, Scougall-Vilchis RJ, Escoffié-Ramírez M, et al. Sociodemographic, socioeconomic, clinical and behavioral factors modifying experience and prevalence of dental caries in the permanent dentition. West Indian Med J 2014; 63: 752-7.

12. Herrera MS, Medina-Solís CE, Avila-Burgos L, Robles-Bermeo NL, Lara-Carrillo E, Lucas-Rincón SE, et al. Treatment needs for dental caries and restorative care index on permanent dentition of Nicaraguan children 6 to 12 years old. West Indian Med J 2017; 65: in press.

13. WHO. Chapter 1: organization of a basic oral health survey. Oral health survey - basic methods. 4th ed. Geneva: World Health Organization; 1997. p. 4-9.

14. Silness J, Löe H. Periodontal disease in pregnancy II. Correlation between oral hygiene and periodontal condition. Acta Odontol Scand 1964; 22: 121-35.

15. Vallejos-Sánchez AA, Medina-Solis CE, Maupomé G, Casanova Rosado JF, MinayaSánchez M, Villalobos-Rodelo JJ, Pontigo-Loyola AP. Socio-behavioral factors influencing tooth brushing frequency in schoolchildren. J Ame Dent Assoc 2008; 139: $743-9$. 
16. Vallejos-Sánchez AA, Medina-Solís CE, Minaya-Sánchez M, Villalobos-Rodelo JJ, Marquez-Corona ML, Islas-Granillo $\mathrm{H}$, et al. Maternal characteristics and treatment needs as predictors of dental health services utilization among Mexican school children. Eur J Paediatr Dent 2012; 13: 307-10.

17. Kolenikov S, Angeles G. The use of discrete data in Principal Component Analysis with applications to socio-economic indices. Working paper No. WP-04-85. CPC/MEASURE; North Carolina: 2004.

18. Ditmyer M, Dounis G, Mobley C, Schwarz E. Inequalities of caries experience in Nevada youth expressed by DMFT index vs. Significant Caries Index (SiC) over time. BMC Oral Health 2011; 11: 12.

19. Mouradian WE, Wehr E, Crall JJ. Disparities in children's oral health and access to dental care. JAMA 2000; 284: 2625-31.

20. Ditmyer M, Dounis G, Mobley C, Schwarz E. A case-control study of determinants for high and low dental caries prevalence in Nevada youth. BMC Oral Health 2010; 10: 24

21. Marinho VC, Chong LY, Worthington HV, Walsh T. Fluoride mouthrinses for preventing dental caries in children and adolescents. Cochrane Database Syst Rev 2016; 7: CD002284.

22. Marinho VC, Worthington HV, Walsh T, Chong LY. Fluoride gels for preventing dental caries in children and adolescents. Cochrane Database Syst Rev 2015; 6: CD002280.

23. Marinho VC, Worthington HV, Walsh T, Clarkson JE. Fluoride varnishes for preventing dental caries in children and adolescents. Cochrane Database Syst Rev 2013; 7: CD002279. 
24. Azevedo MS, Romano AR, Costa VP, da Linhares GS, Lamas RR, Cenci MS. Oral hygiene behavior in 12- to 18-month-old Brazilian children. J Dent Child (Chic) 2015; 82: $128-34$.

25. Huebner CE, Milgrom P. Evaluation of a parent-designed programme to support tooth brushing of infants and young children. Int J Dent Hyg 2015; 13: 65-73.

26. Gopal S, Chandrappa V, Kadidal U, Rayala C, Vegesna M. Prevalence and Predictors of Early Childhood Caries in 3- to 6-year-old South Indian Children--A Cross-sectional Descriptive Study. Oral Health Prev Dent 2016; 14: 267-73.

27. Levin KA, Nicholls N, Macdonald S, Dundas R, Douglas GV. Geographic and socioeconomic variations in adolescent toothbrushing: a multilevel cross-sectional study of 15 year olds in Scotland. J Public Health (Oxf) 2015; 37: 107-15. 
Table 1. Descriptive and bivariate analyses for caries severity

\begin{tabular}{|c|c|c|c|}
\hline Variable & $\begin{array}{c}\text { dmft }+ \text { DMFT }=\text { o } \\
\text { n=394 } \\
\text { Controls }\end{array}$ & $\begin{array}{c}\mathrm{dmft}+\text { DMFT } \geq \mathbf{6} \\
\mathrm{n}=\mathbf{2 8 3} \\
\text { Cases }\end{array}$ & p-value \\
\hline Age & $9.56 \pm 2.13$ & $8.07 \pm 2.13$ & 0.0000 \\
\hline Mother's age & $33.38 \pm 5.93$ & $31.84 \pm 5.90$ & 0.007 \\
\hline \multicolumn{4}{|l|}{ Sex } \\
\hline Boys & $195(55.7)$ & $155(44.3)$ & \\
\hline Girls & $199(60.9)$ & $128(39.1)$ & 0.175 \\
\hline \multicolumn{4}{|l|}{ Birth order } \\
\hline First to third & $332(57.6)$ & $244(42.4)$ & \\
\hline Fourth or more & $62(61.4)$ & $39(38.6)$ & 0.481 \\
\hline \multicolumn{4}{|c|}{ Mother's attitude towards oral health } \\
\hline Negative & $176(60.7)$ & $114(39.3)$ & \\
\hline Positive & $218(56.3)$ & $169(43.7)$ & 0.255 \\
\hline \multicolumn{4}{|c|}{ Frequency of tooth brushing } \\
\hline Less than 7 times/week & $166(49.7)$ & $168(50.3)$ & \\
\hline At least 1 time per day & $228(66.5)$ & $115(33.5)$ & 0.000 \\
\hline \multicolumn{4}{|l|}{ Dentobacterial plaque } \\
\hline Low presence & $21(95.4)$ & $1(4.6)$ & \\
\hline High presence & $373(56.9)$ & $282(43.1)$ & 0.000 \\
\hline \multicolumn{4}{|c|}{ Type of dental care service (last year) } \\
\hline None & $276(72.6)$ & $104(27.4)$ & \\
\hline Preventive & $27(81.8)$ & $6(18.2)$ & \\
\hline Curative & $77(38.7)$ & $122(61.3)$ & \\
\hline Both & $14(21.5)$ & $51(78.5)$ & 0.000 \\
\hline \multicolumn{4}{|c|}{ Family size (number of children) } \\
\hline $1-3$ & $283(57.4)$ & $210(42.6)$ & \\
\hline 4 and more & $111(60.3)$ & $73(39.7)$ & 0.493 \\
\hline \multicolumn{4}{|l|}{ SEP (occupation) } \\
\hline Low & $154(60.2)$ & $102(39.8)$ & \\
\hline Medium & $150(58.4)$ & $107(41.6)$ & \\
\hline High & $90(54.9)$ & $74(45.1)$ & 0.563 \\
\hline \multicolumn{4}{|l|}{ SEP (schooling) } \\
\hline Low & $138(55.6)$ & $110(44.4)$ & \\
\hline Medium & $119(58.0)$ & $86(42.0)$ & \\
\hline High & $137(61.2)$ & $87(38.8)$ & 0.478 \\
\hline
\end{tabular}

